MATEC Web of Conferences 13, 04010 (2014)

DOI: $10.1051 /$ matecconf/ 20141304010

(C) Owned by the authors, published by EDP Sciences, 2014

\title{
Evaluation of Spur Gear Pair on Tooth Root Bending Stress in Radial Misalignment Contact Condition
}

\author{
M.R.Lias ${ }^{1, \mathrm{a}}$, M.Awang ${ }^{2}$, T V V L N Rao ${ }^{3}$, M.F.A Ahmad ${ }^{4}$ and S. Patil ${ }^{5}$ \\ Mechanical Engineering Department, Universiti Teknologi PETRONAS, Bandar Seri Iskandar, 31750 \\ Tronoh, Perak, Malaysia
}

\begin{abstract}
This paper evaluates the effects of radial misalignment contact on the tooth root bending stress values of spur gear pair during the gear meshing cycle. Radial misalignment $(\mathrm{H})$ is denoted as the deviation of the pinion nominal position with respect to the gear tooth along the pinion axis to the gear which happened from manufacturing assembly errors (AE). A model based on involute 3D parametric CAD geometry, of spur gear design ISO 6336:2006 is analysed with allowable AE values from minimum 10 $\mu \mathrm{m}$ to maximum $40 \mu \mathrm{m}$ with Finite-Element Method (FEM) model based methodology using a dynamics module from ANSYS. Main parameters of interest are the Tooth root bending stress (TRBS) in $\mathrm{H}$ condition with $\mathrm{AE}$ along the critical region with respect to face width of pinion-gear section. A comparison between standard High point single tooth contact models (HPSTC) to this model showed a good agreement that $\mathrm{H}$ with AE had great influence on TRBS as the values' increase. Radial misalignment influence factor (RMIF) was introduced as indication of TRBS values in consideration of $\mathrm{H}$ due to AE shows and inverted patterns higher for pinion, give a good justification that the pinion is weaker compared to the gear.
\end{abstract}

\section{Introduction}

Most mechanical design practice that involved with rotating part such as gears needs a lot of intentions due to its complicated art of motion. As the system runs, the meshing contact pinion to gears is a very complex dynamics problem. The elastic material whirling motion, crucial speed and assembly errors (AE) always lead to the radial misalignments contacts in between the face width of the gear tooth. These contact impacts tooth root bending stress (TRBS) value and distribution along the important maximum stress plane at $30^{\circ}$ angles for each section tooth. The cyclic loading behaviour furthermore, will leads bending fatigue failure happened and reduce the service life of the gears.

Misalignment in gear meshing contact is described as a small deviation or error in a pinion-gear assembles theoretically to the actually happened [1]. Radial misalignment $(H)$ is denoted as the deviation of the pinion nominal position with respect to the gear tooth along the pinion axis to the gear happened from assembly errors (AE).This position is described based on the coordinate system such as Figure 1 in between contact of the pinion to the gear as suggested by [2]. A positive $\mathrm{H}$ error is

\footnotetext{
${ }^{a}$ Corresponding author : rizal_lias@ptsb.edu.my
}

This is an Open Access article distributed under the terms of the Creative Commons Attribution License 2.0, which permits unrestricted use, distribution, and reproduction in any medium, provided the original work is properly cited. 
movement of the pinion away from the gear axis contributed from AE due to manufacture allowable tolerance in between $10 \mu \mathrm{m}$ to $40 \mu \mathrm{m}$ [3] parallel to the pinion and gear tooth.

Experiment had been conducted by Timmers [4] in order to correlate the effect of AE to TRBS in early 70 's. Their result showed that positive $\mathrm{H}$ weakened the structure while negative $\mathrm{H}$ reduce efficiencies of the gear tooth contact and bending strength. Recent advances in computerization make FEM become a trend to solve the problem related to the gearing. Started late 1980s, Townsend et.al [5] describe a new approach to calculate maximum TRBS with FEM. Their use single model teeth with asymmetry load allowed calculation of stress distribution in the adjacent teeth. Kramberger et al. [6] applied Boundary element method (BEM) analyzing the maximum TRBS of thin-rim spur gear. Shun Li [3] continue the research with quasi static loading model using load sharing ratio (LSR) method with tooth modifications. Though, there are many research continues comes out in this recent decade with TRBS as the main subject[7], so far, an effective detail of $\mathrm{H}$ due to AE is still sparse in shadowed.

Thus, this paper determines to focus on this problem in detail with a significant FEM methodology using ANSYS tool. A full model of involutes 3D parametric CAD geometry based on mathematical standard formulation of ISO 6336:2006 spur gear design is develop to analyze $\mathrm{H}$ with allowable $\mathrm{AE}$ values from minimum $10 \mu \mathrm{m}$ to maximum $40 \mu \mathrm{m}$. Result is then compared with static High point single tooth contact (HPSTC) model from [8] with no H. Radial misalignment influence factor (RMIF) is introduced as indication of TRBS in H condition due to AE.

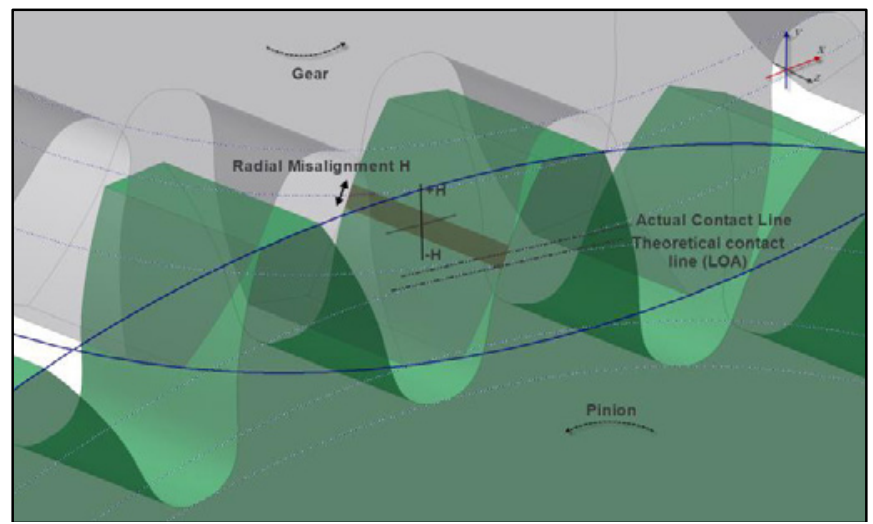

Figure 1. Illustration of pinion gear meshing in radial misalignment contact $(\mathrm{H})$

\section{Description of the Finite Element Model}

The physical model based is obtained from involutes parametric 3D CAD geometry of spur gear design ISO 6336:2006 conventional design module as Table 1. It consists of one pinion and one gear in full teeth with material SCM415 from [3]. The pinion act as a drive gear was subjected to an angular velocity $\omega=1 \mathrm{rad} / \mathrm{s}$ counter clockwise. A torque, $\mathrm{T}=10 \mathrm{Nm}$ is applied to the gear in order to simulate the dynamics load. The displacement of node changes over time during the analysis, which can be described as:

$$
\{q\}=q(x, y, z, t)
$$

where, $q$ is the displacement of a node, $x, y, z$ are three coordinates respectively, $t$ is time. For the whole analysis model, elements are under the status of force equilibrium and the displacement of every node is also in equilibrium. When the gear pair is under external load, based on the principle of force equilibrium the relationship between the displacement node and external dynamics load can be expressed as:

$$
[K]\{q\}=F i(t)
$$


where, $\{q\}$ is the displacement node, $[K]$ is a total stiffness matrix of the element, which was the set of blocking stiffness matrix of elements mesh generated from the model. Fi( $t)$ is the matrix of external dynamics load history as function of time.
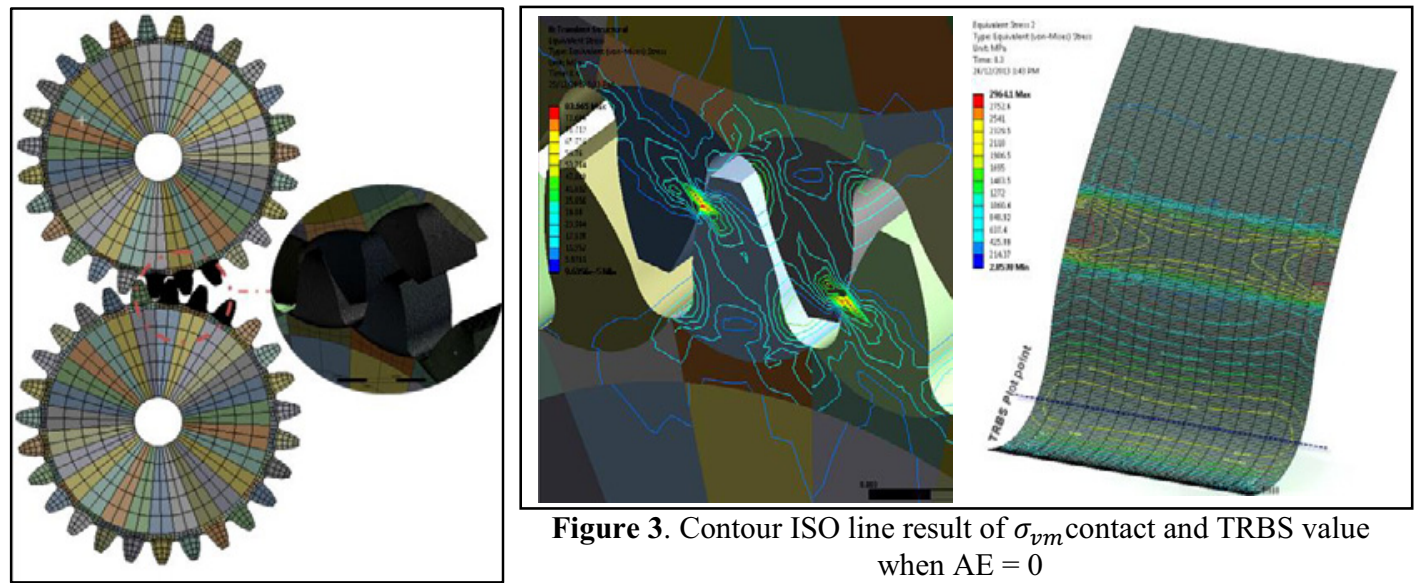

Figure 3. Contour ISO line result of $\sigma_{v m}$ contact and TRBS value when $\mathrm{AE}=0$

Figure 2. Element meshing of FEM model

Both pinion-gears are meshed with symmetrical FEM mapped element as Figure 2 with 192 part bodies. Joint revolute UZ is applied as constraint on the hollow region for both pinion-gears. Contact element Augmented langrage model [9] is use with refine mesh $0.1 \mathrm{~mm}$ in between 3 teeth of the model. It is initially arranged in perfectly aligned between pinion to gear, where TRBS is allowed. Then, AE value between 10, 20, 30 and $40 \mu \mathrm{m}$ gradually applied as $\mathrm{H}$ simulation. APDL mechanical module in ANSYS is use in order to calculate the value of stress for each node and element. TRBS is then plotted at the critical region.

Table 1.Gear Model parameters

\begin{tabular}{|c|c|c|c|c|}
\hline Parameter & Symbol & Unit & Pinion & Gear \\
\hline \multicolumn{5}{|c|}{ Geometry } \\
\hline Normal Module & $\mathrm{m}$ & $\mathrm{mm}$ & \multicolumn{2}{|c|}{5} \\
\hline Normal Pressure Angle & $\alpha_{n}$ & degree & \multicolumn{2}{|c|}{$20^{0}$} \\
\hline Number of Teeth & $\mathrm{z}$ & & 27 & 27 \\
\hline Center Distance & $a_{x}$ & \multirow{2}{*}{$\mathrm{mm}$} & \multicolumn{2}{|c|}{135} \\
\hline Face width & $\mathrm{b}$ & & \multicolumn{2}{|c|}{12} \\
\hline \multicolumn{5}{|c|}{ Load } \\
\hline Torque & $\mathrm{T}$ & $\mathrm{Nm}$ & \multicolumn{2}{|c|}{10} \\
\hline Speed & $\mathrm{N}$ & $\mathrm{rad} / \mathrm{s}$ & \multicolumn{2}{|c|}{1} \\
\hline \multicolumn{5}{|c|}{ Material SCM415 } \\
\hline Modulus of Elasticity & $\mathrm{E}$ & $\mathrm{GPa}$ & \multicolumn{2}{|c|}{206} \\
\hline Poisson's Ratio & $\mu$ & & \multicolumn{2}{|c|}{0.300} \\
\hline Density & $\rho$ & $\mathrm{kg} / \mathrm{m}^{3}$ & \multicolumn{2}{|c|}{7830} \\
\hline
\end{tabular}

According to Haiba et.al[10] stress of the dynamic mechanical system can be estimated by separated time step using quasi-static stress analysis approach, which:

$$
\begin{gathered}
\sigma_{x}(t)=\sum_{i=1}^{n} \sigma_{x i} F_{i}(t), \sigma_{y}(t)=\sum_{i=1}^{n} \sigma_{y i} F_{i}(t), \sigma_{z}(t)=\sum_{i=1}^{n} \sigma_{z i} F_{i}(t) \\
\tau_{x y z}(t)=\sum_{i=1}^{n} \tau_{x y z i} F_{i}(t)
\end{gathered}
$$


where, $\mathrm{n}$ is the number of applied load histories and $\sigma_{x i}(t), \sigma_{y i}(t), \sigma_{z i}(t), \tau_{x y z i}(t)$ are the stress due to a unit load in a function of time. TRBS is then calculated based on Von misses yield criteria $\sigma_{v m}$ for each specific nodal in normal direction for each load history time $F i(t)$. It is meant that the analysis is based on certain real time dynamics moment, for this case, is the highest TRBS only.

\section{Results and Discussion}

TRBS calculations of $\mathrm{H}$ with effect of $\mathrm{AE}$ are performed by dynamics condition with $10 \mathrm{Nm}$ load at gear with $1 \mathrm{rad} / \mathrm{s}$ speed of the pinion. Equivalent Von-misses criteria are plotted at critical region as Figure 3 based on prescription describe from [8]. From Figure 4 and 5, it is clearly shown that when $\mathrm{AE}=0$, value of TRBS is much lower compared with static HPSTC model. Then the value gradually increased with respect to $\mathrm{AE}$ in between $10 \mu \mathrm{m}$ to $40 \mu \mathrm{m}$. In Figure 5, a very similar pattern of TRBS was plotted for the gear, the only different is the value of the stress, which was lower. As Figure 6 and 7, RMIF was introduced as an indication of the effect $\mathrm{H}$ from AE on TRBS. It is calculated by dividing the highest value of TRBS when AE existed to the value when pinion-gear in perfect contact or $\mathrm{AE}=0$. Relationship between these factors found that the RMIF value of AE on TRBS is maximum 1.52 when $\mathrm{AE}=40 \mu \mathrm{m}$ for pinion and 1.225 for the gear. The graph of maximum TRBS to RMIF factor had shown an inverted pattern between each other's. These values can be describe as a good justification as result from [7] that the pinion is weaker compared to the gear, thus the factor should be more in term of value.

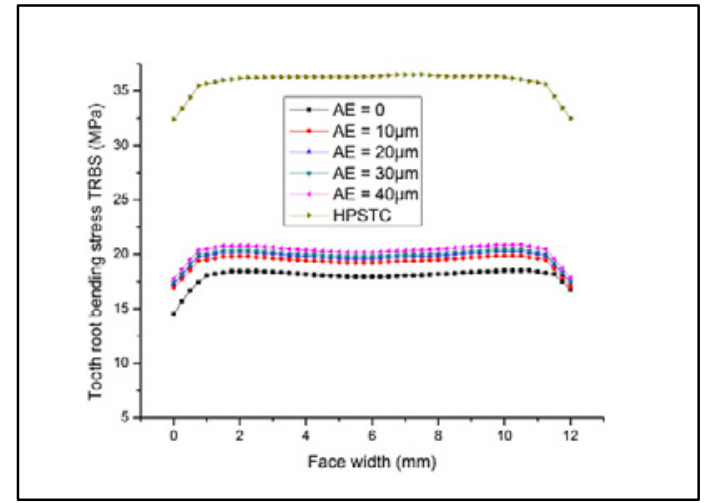

Figure 4. Tooth root bending stress across critical region for the pinion

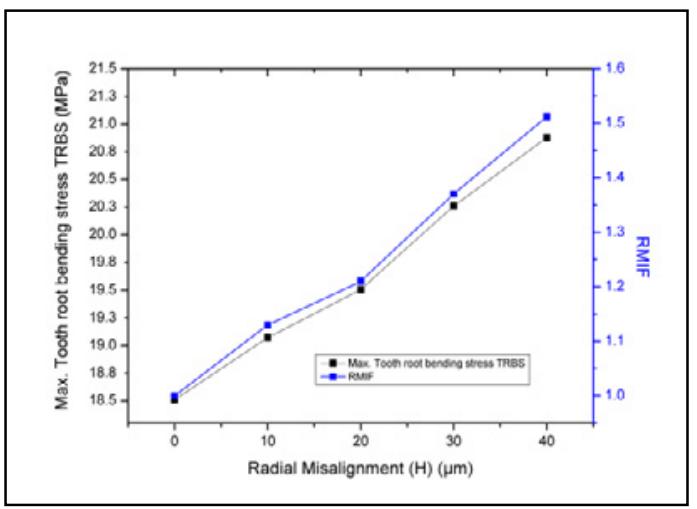

Figure 6. Maximum TRBS to $(\mathrm{H})$ with RMIF value for pinion

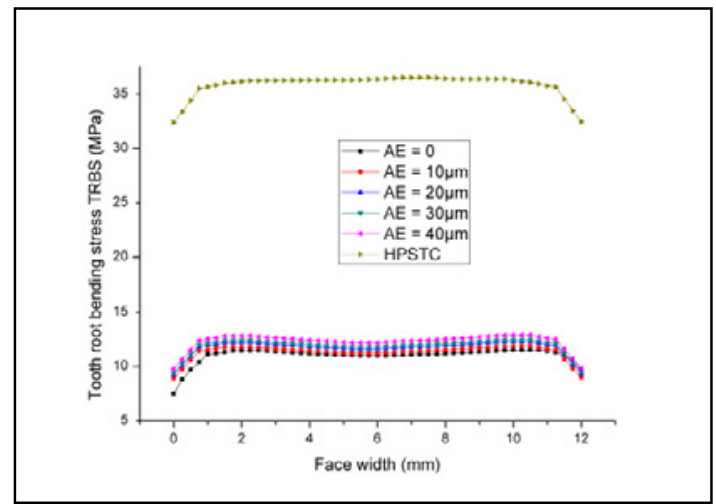

Figure 5. Tooth root bending stress across critical region for the gear

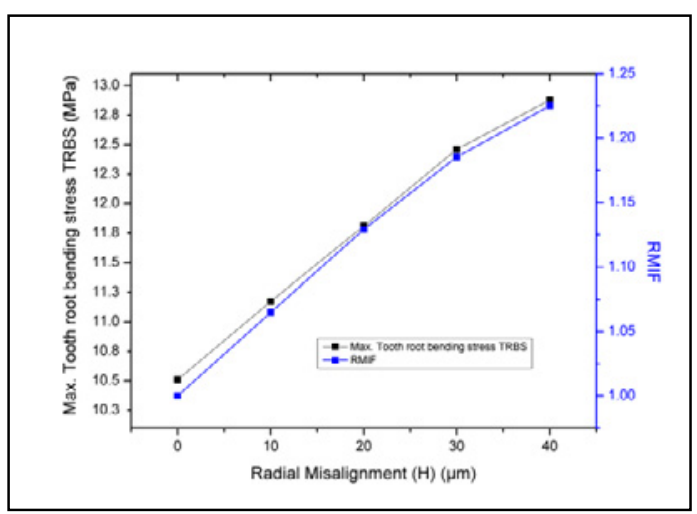

Figure 7. Maximum TRBS to $(\mathrm{H})$ with RMIF value for gear 


\section{Conclusions}

In this paper, FEM model based analysis was conducted to evaluate the effect of radial misalignment contact $(\mathrm{H})$, due to assembly error (AE), on the tooth root bending stress (TRBS) values of spur gear pair during gear meshing cycle. Major contribution in this paper can be summarized as:

1. The propose of this FEM model and methodology are adequate in order to conduct a real time dynamics simulation to define the value of TRBS in $\mathrm{H}$ condition due to AE.

2. RMIF influence factor of $H$ on TRBS shows and inverted patterns where the value of pinion is higher compared to the values of gear. These gave a justification that the pinion is more subjected to $\mathrm{AE}$ effect, weaker, compared to the gear, which mean its need more intention in mechanical gear design practice.

\section{Acknowledgements}

This research work is funded by Exploratory Research Grant Scheme - Ministry of Higher Education Malaysia (ERGS-MOHE) under grant ERGS 0153AB-I14. The authors greatly appreciate the support provided by MOHE and Universiti Teknologi PETRONAS for the facilities, system support and financial aid for this research.

\section{References}

1. M.R. Lias, T.V.V.L.N.R, M. Awang and M.A. Khan, The Stress Distribution of Gear Tooth Due to Axial Misalignment Condition, Journal of Applied Sciences, 12, pp. 2404-2410, (2012)

2. A. Palermo, D. Mundo, R. Hadjit, and W. Desmet, Multibody element for spur and helical gear meshing based on detailed three-dimensional contact calculations, Mechanism and Machine Theory, 62, pp. 13-30, (2013)

3. S. Li, Effects of machining errors, assembly errors and tooth modifications on loading capacity, load-sharing ratio and transmission error of a pair of spur gears, Mechanism and Machine Theory, 42, pp. 698-726, (2007)

4. J. Timmers, Der Einflussfertigungstechnisch-und lastbedingterAchsversetzungen in Stirnradgetrieben auf die Zahnverformung, English Translation, Mechanism and Machine Theory, 87, pp. 1771-1778, (1965)

5. J. J. Coy, D. P. Townsend, and H. H. Coe, Results of NASA/Army transmission research, DTIC Document (1987)

6. J. Kramberger, Šraml, M., Potrč, I., and Flašker, J., Numerical Calculation of Bending Fatigue Life of Thin-Rim Spur Gears, Eng. Fract. Mech.,71 pp. 647-656, (2004)

7. Y. Z. Xu, Z. X. Wu, S. A. Tian, and Y. J. Hua, Three-Dimensional Analyses of Spur Gear Bending Stresses by Global-Local Finite Element Technique, Applied Mechanics and Materials, 365, pp. 309-313, (2013)

8. A. Kawalec, D. Ceglarek, and J. Wiktor, Comparative Analysis of Tooth-Root Strength Using ISO and AGMA Standards in Spur and Helical Gears With FEM-based Verification, Journal of Mechanical Design, 128, pp. 1141-1158, (2005)

9. A. W. 11.0, ANSYS Modeling and Meshing Guide. USA: ANSYS, Inc., (2006)

10. B. Haiba M., DC, Brooks, PC, Levesley, MC ., Review of life assessment techniques applied to dynamically loaded automotive components, Computers and Structures,2, pp. 481-494, (2002) 